\title{
Neural correlates of delusional infestation responding to aripiprazole monotherapy: a case report
}

\author{
Laura Ponson ${ }^{1,2}$ \\ Frédéric Andersson' \\ Wissam El-Hage ${ }^{1,2}$ \\ 'Université François-Rabelais de \\ Tours, Inserm, Imagerie et Cerveau \\ UMR U930, Tours, France, ${ }^{2} \mathrm{CHRU}$ \\ de Tours, Clinique Psychiatrique \\ Universitaire, Tours, France
}

This article was published in the following Dove Press journal:

Neuropsychiatric Disease and Treatment

2 February 2015

Number of times this article has been viewed

Background: The pathophysiology and appropriate pharmacological interventions for delusional infestation remain unknown.

Case presentation: Here, we report a case of primary delusional infestation successfully treated with aripiprazole. We performed functional magnetic resonance imaging (fMRI) to investigate brain structures and functional modifications. Before antipsychotic treatment, pre- versus post-treatment fMRI images revealed a marked increase in brain activation in the supplementary motor area (SMA).

Conclusion: Our results highlight the efficacy and safety of aripiprazole in the treatment of delusional infestation and the possible role of SMA dysfunction in delusional infestation. Indeed, our results suggest that psychiatric improvement of delusional infestation is associated with normalization of brain activity, particularly in the SMA.

Keywords: supplementary motor area, antipsychotics, fMRI

\section{Introduction}

Delusional infestation is characterized by the firm belief that pathogens are infesting one's skin. It is a relatively rare syndrome. The frequency of delusional infestation is not entirely clear, but it is estimated that the average dermatologist will manage 2-3 patients with delusional infestation every 5 years. ${ }^{1}$ Typically, patients have abnormal cutaneous symptoms (including itching, biting, or formication) or describe a generalized moving sensation, which eventually progresses to the internal organs via the patient's natural orifices. Patients often demonstrate self-destructive behavior in an effort to rid the pathogens from under their skin. This may lead to excoriations, ulcerations, and serious secondary infections. ${ }^{2}$ Structural brain abnormalities in patients with delusional infestation have mainly been described in case reports; ${ }^{3,4}$ the patients in these case reports often have an underlying encephalopathy or previous stroke. ${ }^{5-8}$ Freudenmann et al explored the neural basis of delusional infestation, showing low-level evidence of possible dysfunctional fronto-striato-thalamo-parietal network, ie, brain regions involved in judgment (frontal cortex), body perception (dorsal loop and parietal somatic cortices), and sensory gating (thalamus). ${ }^{4}$ Nevertheless, there are several other circumstances that have been associated with its appearance, including several other neurologic and endocrine disorders, ${ }^{9}$ medications, and abuse of substances. ${ }^{10,11}$

Although the pathophysiology and appropriate pharmacological interventions in delusional infestation remain unknown, antipsychotic medications are commonly used. ${ }^{9}$ We report here a case of primary delusional infestation treated with aripiprazole, a second-generation antipsychotic. Functional magnetic resonance imaging (fMRI)
Correspondence: Wissam El-Hage Clinique Psychiatrique Universitaire, CHRU de Tours, Boulevard Tonnellé, 37044 Tours Cedex 9, France Email wissam.elhage@univ-tours.fr 
was performed before and after an 8-month period to further investigate the clinical evolution and functional correlates associated with delusional infestation.

\section{Case report}

A 68-year-old woman with no psychiatric history was referred by her dermatologist for a psychiatric consultation. The patient complained of burning, itching, and generalized pain in the region of her head and face. She described persistent and spreading abnormal tactile sensations. In addition, the patient complained of the rise in incidence of these persistent mobile skin vesicles. She had strong conviction that the vesicles were infested by some tiny pathogens (vermin). The patient was so disturbed by these complaints that her quality of life had progressively deteriorated. She spent much of her time trying to get rid of the vesicles and kill the pathogens, using mechanical force and chemical self-cleaning (disinfectants, alcohol, creams, soap). The patient's symptoms had persisted for the past 2 years. She consulted several general practitioners, dermatologists, and microbiologists but avoided psychiatrists. Despite seeing several doctors and dermatologists who performed two biopsies and a lymphoscintigraphy exam, she was never given an accurate diagnosis. No medical or microbiological evidence was found for this.

On psychiatric evaluation, the patient described a history of posttraumatic stress disorder symptoms, lasting for 3-4 years, following the death of her mother (who died from primary skin carcinoma of her face). Although the patient exhibited few current symptoms of posttraumatic stress disorder, she did express having some nightmares and more frequently, diurnal 'flashbacks' in which her own face was superimposed with that of her mother's degraded face. These 'flashbacks' can be also interpreted as visual illusions or hallucinations. The patient did not show any signs consistent with a chronic mood disorder or other psychosis. However, she clearly expressed her fear of having the same fate as her mother at the same age, and the fear of having a disfigured face.

We decided to start the patient on aripiprazole ( $5 \mathrm{mg} /$ day). Although there have been no controlled clinical trials, there is significant evidence for effectiveness of second-generation antipsychotics in the treatment of this syndrome, eg, risperidone, ${ }^{12-15}$ aripiprazole, ${ }^{13}$ and blonanserin ${ }^{3}$ in the treatment of delusional infestation. We chose aripiprazole because of its mechanism of action and its good clinical tolerance profile. Indeed, aripiprazole has a unique pharmacological effect on the dopamine neurotransmission system (partial agonist at dopamine D2 and D3 receptors).
An fMRI was performed before and after the treatment period. Scanning was performed on a $3 \mathrm{~T}$ Siemens Verio MRI scanner (Siemens AG, Erlangen, Germany). Functional images were acquired using a single-shot echo planar imaging (EPI) sequence sensitive to blood oxygen level-dependent (BOLD) contrast (repetition time $[\mathrm{TR}]=3$ seconds; echo time $[\mathrm{TE}]=30 \mathrm{~ms}$; flip angle $=90^{\circ} ; 50$ contiguous slices; $2.5 \mathrm{~mm}$ thickness; $2.5 \times 2.5 \mathrm{~mm}$ in-plane resolution; field of view [FOV] $=240 \mathrm{~mm}$ ). The patient performed a visual mental imagery task with a block paradigm, which included 13 rest condition blocks (lasting 12 seconds) and four different mental imagery conditions (lasting 15 seconds, each repeated three times): 1) imagery of her own hand, 2) her own face, 3) her husband's face, and 4) her mother's face.

We obtained written informed consent from the patient prior to performing any procedures. Moreover, written informed consent was obtained from the patient for publication of this case report. A copy of the written consent is available for review by the editor of this journal.

\section{Results}

The patient's complaints progressively decreased in severity and she reported a significant increase in her quality of life (Table 1). After 2 months of aripiprazole treatment, no side effects were noted and the patient stated that most of her vesicles had disappeared. A few of the patient's complaints remained, however, including persistent itching and aching. The medication was increased to $15 \mathrm{mg}$ /day, which completely resolved all of the patient's complaints. A follow-up

Table I Clinical measures

\begin{tabular}{lll}
\hline & $\begin{array}{l}\text { Session I: } \\
\text { before treatment }\end{array}$ & $\begin{array}{l}\text { Session 2: } \\
\text { after } 8 \text { months }\end{array}$ \\
\hline MINI 5.0 & & \\
$\quad$ Current MDE, n & 1 & 0 \\
Current suicidal risk, $n$ & 1 & 0 \\
Other comorbidities, $n$ & 0 & 0 \\
SAPS, score & 14 & 6 \\
SANS, score & 21 & 10 \\
MADRS, score & 18 & 8 \\
HAM-A psychic anxiety, score & 13 & 8 \\
HAM-A somatic anxiety, score & 0 & 4 \\
CAPS, total score & 20 & 12 \\
Re-experiencing, score & 3 & 0 \\
Avoidance, score & 8 & 5 \\
Hyperarousal, score & 9 & 7 \\
\hline
\end{tabular}

Abbreviations: CAPS, clinician-administered PTSD (posttraumatic stress disorder) scale; HAM-A, Hamilton Anxiety Rating Scale; MADRS, Montgomery-Åsberg Depression Rating Scale; MDE, major depressive episode; MINI, Mini-international neuropsychiatric interview; SANS, Scale for the Assessment of Negative Symptoms; SAPS, Scale for the Assessment of Positive Symptoms. 


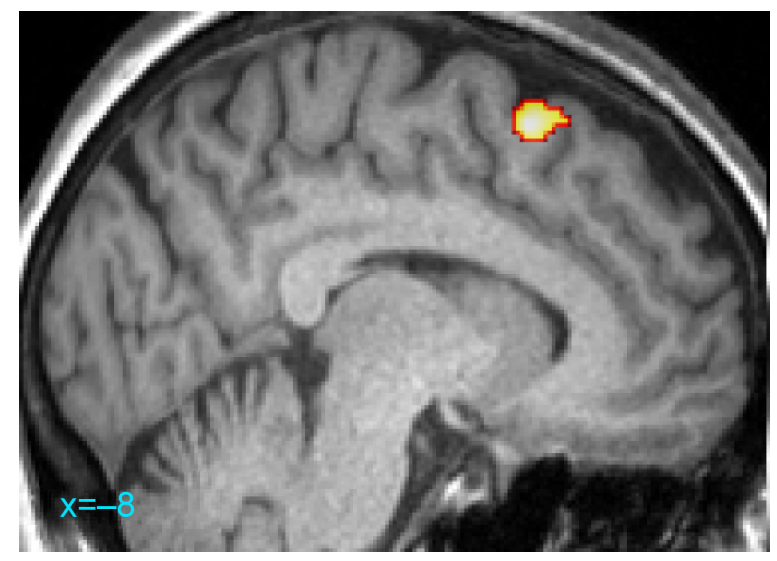

Figure I Antipsychotic treatment effects during own face mental imagery task. Note: The supplementary motor area $(-8,18,58)$ was more activated before than after antipsychotic treatment (with aripiprazole).

psychiatric evaluation confirmed marked generalized clinical improvement.

When comparing pre- and post-treatment imaging, the supplementary motor area (SMA) was significantly more activated for all the mental facial imagery tasks (Figure 1). Upon recovery, other regions of brain activity were observed, which corresponded to the abnormal pre-treatment hypoactivation. All of the activations are presented in terms of cluster size, $P$-value, Montreal Neurological Institute (MNI) coordinates, and $Z$-score in Table 2.

\section{Discussion}

Our results highlight the efficacy and safety of aripiprazole in the treatment of delusional infestation and the possible role of SMA dysfunction in delusional infestation.

Prior to treatment, the SMA was the only region that was significantly more active. Following treatment, we found a marked decrease in the activation of this area; this result was attributed to the dysfunction in the region of the SMA during delusional infestation. An alteration of the SMA may adversely affect how we perceive and adapt to our surroundings. In a previous study, Saugstad highlighted the role of the SMA in psychosis, ${ }^{16}$ suggesting that psychosis is due to an abnormally functioning SMA; in such cases, there is relatively decreased function of the excitatory synapses, which creates silent spots in the region of the SMA. The varying localizations of these silent spots may explain the great variability in schizophrenia. Our results suggest that SMA dysfunction may be implicated in this case of delusional infestation. Although the mechanism regarding the modification of SMA activity remains unclear, functional readjustment in this area may contribute to the improvement of clinical symptoms. Future studies should investigate different therapeutic techniques, including the effects of repetitive transcranial magnetic stimulation on the SMA in the treatment of delusional infestation.

Table 2 Between-session comparisons of treatment effect on all tasks

\begin{tabular}{|c|c|c|c|c|c|}
\hline Mental imagery & Brain region & Size $\left(\mathrm{mm}^{3}\right)$ & $P$-value & Z-score & MNI coordinates \\
\hline \multicolumn{6}{|c|}{ Session I > session 2} \\
\hline Own hand & - & NS & - & - & - \\
\hline Own face & Supplementary motor area & 142 & 0.04 & 3.24 & $-8,18,58$ \\
\hline Mother's face & Supplementary motor area & 125 & 0.05 & 3.43 & $-8,18,58$ \\
\hline Husband's face & Supplementary motor area & 124 & 0.05 & 3.46 & $-8,18,58$ \\
\hline \multicolumn{6}{|c|}{ Session $2>$ session I } \\
\hline \multirow[t]{3}{*}{ Own hand } & Cerebellum & 694 & $<0.001$ & 3.80 & $-18,-64,12$ \\
\hline & Left fusiform & 160 & 0.03 & 3.71 & $-34,-24,-22$ \\
\hline & Right precuneus & 191 & 0.02 & 3.05 & $2,-70,58$ \\
\hline \multirow[t]{3}{*}{ Own face } & Cerebellum & $\mathrm{I}, 424$ & $<0.001$ & 4.09 & $-18,-64,-12$ \\
\hline & Cerebellum & 200 & 0.01 & 4.01 & $-32,-24,-22$ \\
\hline & Parahippocampus & 370 & $<0.001$ & 3.41 & $-30,-62,-28$ \\
\hline \multirow[t]{4}{*}{ Mother's face } & Parahippocampus & 123 & 0.05 & 3.73 & $-30,-26,-22$ \\
\hline & Parahippocampus & 1,222 & $<0.001$ & 3.50 & $34,-76,4$ \\
\hline & Cerebellum & 148 & 0.03 & 3.14 & $-28,-58,46$ \\
\hline & Left precuneus & 126 & 0.05 & 2.76 & $-2,-48,66$ \\
\hline \multirow[t]{3}{*}{ Husband's face } & Vermis & 1,425 & $<0.001$ & 3.81 & $4,-66,-8$ \\
\hline & Cerebellum & 142 & 0.04 & 3.34 & $-30,-56,-46$ \\
\hline & Left precuneus & 165 & 0.03 & 2.98 & $-2,-48,66$ \\
\hline
\end{tabular}

Notes: $P<0.01$ (voxel level) with cluster-wise correction $(P<0.05)$; $P$-values given for clusters.

Abbreviations: $\mathrm{MNI}$, Montreal Neurological Institute; NS, not significant. 
After recovery, different areas of the brain were found to be significantly more activated than during the delusional episode: the cerebellum, which is known for its role in attention and mental imagery, the fusiform in body recognition, and the precuneus in reference to the self ${ }^{17,18}$ and somatization. ${ }^{19}$ The precuneus was found to be more activated, with the exception of the patient's face condition. Despite the difficulty of interpreting these results, functional modifications in such regions cannot be ignored due to their association with psychotic disorders such as altered feelings of self and body incarnation.

In conclusion, this case report confirms the efficacy and safety of using aripiprazole in treating delusional infestation. The possible mechanism of such successful treatment depends on its partial agonist activity at the D2/D3 receptors. Thus, aripiprazole works as a dopamine stabilizer, reducing dopamine activity in dopaminergic systems where the neurotransmitter levels are high, and raising dopamine activity in dopaminergic systems where the neurotransmitter levels are low. According to Freudenmann et $\mathrm{al}^{4}$ aripiprazole treatment in delusional infestation is associated with blocking $63 \%-78 \%$ of striatal D2 receptors, which was both effective and well-tolerated. Moreover, the occupancy rate appeared comparable to the occupancy rate that has been established for treating schizophrenia. In our study, we found that dysfunction of the SMA may be associated with the manifestations of delusional infestation; therefore, normalization of the SMA activity may lead to improvement of the symptoms of delusional infestation.

\section{Acknowledgment}

We thank Professor Jean-Philippe Cottier for his helpful comments on the design of the experiment.

\section{Author contributions}

FA and WEH participated in the design of the study. LP and WEH drafted the manuscript. LP and FA performed the data analysis. All authors contributed to and have approved the final manuscript.

\section{Disclosure}

WEH has received honoraria for conferences and consulting from AstraZeneca, Bristol-Myers Squibb, Eli Lilly, Janssen-Cilag, Lundbeck, and Otsuka. LP and FA report no proprietary or commercial interest in any product mentioned or concept related to this article. This study did not receive funding from any source.

\section{References}

1. Koo J, Lee CS. Delusions of parasitosis. A dermatologist's guide to diagnosis and treatment. Am J Clin Dermatol. 2001;2(5):285-290.

2. Heller MM, Wong JW, Lee ES, et al. Delusional infestations: clinical presentation, diagnosis and treatment. Int J Dermatol. 2013; 52(7):775-783.

3. Bhatia MS, Rathi A, Jhanjee A. Delusional infestation responding to blonanserin. J Neuropsychiatry Clin Neurosci. 2013;25(4):E54.

4. Freudenmann RW, Kölle M, Huwe A, et al. Delusional infestation: neural correlates and antipsychotic therapy investigated by multimodal neuroimaging. Prog Neuropsychopharmacol Biol Psychiatry. 2010;34(7):1215-1222.

5. Blasco-Fontecilla H, Bragado Jiménez MD, García Santos LM, Barjau Romero JM. Delusional disorder with delusions of parasitosis and jealousy after stroke: treatment with quetiapine and sertraline. $J$ Clin Psychopharmacol. 2005;25(6):615-617.

6. Hanihara T, Takahashi T, Washizuka S, Ogihara T, Kobayashi M. Delusion of oral parasitosis and thalamic pain syndrome. Psychosomatics. 2009;50(5):534-537.

7. Nagaratnam N, O'Neile L. Delusional parasitosis following occipito-temporal cerebral infarction. Gen Hosp Psychiatry. 2000; 22(2):129-132.

8. Prakash R, Gandotra S, Singh LK, Das B, Lakra A. Rapid resolution of delusional parasitosis in pellagra with niacin augmentation therapy. Gen Hosp Psychiatry. 2008;30(6):581-584.

9. Huber M, Lepping P, Pycha R, Karner M, Schwitzer J, Freudenmann RW. Delusional infestation: treatment outcome with antipsychotics in 17 consecutive patients (using standardized reporting criteria). Gen Hosp Psychiatry. 2011;33(6):604-611.

10. Stanciu CN, Penders TM, Oxentine HN. Delusional infestation following misuse of prescription stimulants. Psychosomatics. Epub 2014 Mar 20.

11. Rosenzweig I, Ramachandra P, Freer J, Wong M, Pieters T. Delusional parasitosis associated with donepezil. J Clin Psychopharmacol. 2011;31(6):781-782.

12. Bennàssar $\mathrm{A}$, Guilabert $\mathrm{A}, \mathrm{Alsina} \mathrm{M}$, Pintor L, Mascaró JM Jr. Treatment of delusional parasitosis with aripiprazole. Arch Dermatol. 2009;145(4):500-501.

13. Huang WL, Chang LR. Aripiprazole in the treatment of delusional parasitosis with ocular and dermatologic presentations. J Clin Psychopharmacol. 2013;33(2):272-273.

14. Kumbier E, Höppner J. Neuroleptische Behandlung des Dermatozoenwahns [The neuroleptic treatment of delusional parasitosis: first experiences with aripiprazole]. Hautarzt. 2008;59(9):728-730, 732-733. German.

15. Narayan V, Ashfaq M, Haddad PM. Aripiprazole in the treatment of primary delusional parasitosis. Br J Psychiatry. 2008;193(3):258.

16. Saugstad LF. What is a psychosis and where is it located? Eur Arch Psychiatry Clin Neurosci. 2008;258 Suppl 2:111-117.

17. Albrecht K, Volz KG, Sutter M, von Cramon DY. What do I want and when do I want it: brain correlates of decisions made for self and other. PLoS One. 2013;8(8):e73531.

18. Van der Meer L, de Vos AE, Stiekema AP, et al. Insight in schizophrenia: involvement of self-reflection networks? Schizophr Bull. 2013;39(6): $1288-1295$.

19. Lemche E, Giampietro VP, Brammer MJ, Surguladze SA, Williams SC, Phillips ML. Somatization severity associated with postero-medial complex structures. Sci Rep. 2013;3:1032. 


\section{Publish your work in this journal}

Neuropsychiatric Disease and Treatment is an international, peerreviewed journal of clinical therapeutics and pharmacology focusing on concise rapid reporting of clinical or pre-clinical studies on a range of neuropsychiatric and neurological disorders. This journal is indexed on PubMed Central, the 'PsycINFO' database and CAS, and is the official journal of The International Neuropsychiatric Association (INA). The manuscript management system is completely online and includes a very quick and fair peer-review system, which is all easy to use. Visit http://www.dovepress.com/testimonials.php to read real quotes from published authors.

Submit your manuscript here: http://www.dovepress.com/neuropsychiatric-disease-and-treatment-journal 